Article

\title{
A Framework for Design and Operation Optimization for Utilizing Low-Grade Industrial Waste Heat in District Heating and Cooling $^{+}$
}

\author{
Lingwei Zhang $^{1}$, Yufei Wang ${ }^{1, *}$ and Xiao Feng ${ }^{2}$ \\ 1 State Key Laboratory of Heavy Oil Processing, China University of Petroleum, Beijing 102249, China; \\ 2019210608@student.cup.edu.cn \\ 2 School of Chemical Engineering \& Technology, Xi'an Jiaotong University, Xi'an 710049, China; \\ xfeng@mail.xjtu.edu.cn \\ * Correspondence: wangyufei@cup.edu.cn \\ $+\quad$ This paper is an extended version of our paper published in Chemical Engineering Transactions for The 23rd \\ Conference on Process Integration, Modelling and Optimisation for Energy Saving and Pollution Reduction \\ (PRES'20), Xi'an, China, 17-21 August 2020; Volume 81, pp. 511-516.
}

check for updates

Citation: Zhang, L.; Wang, Y.; Feng, $X$. A Framework for Design and Operation Optimization for Utilizing Low-Grade Industrial Waste Heat in District Heating and Cooling. Energies 2021, 14, 2190. https:// doi.org/10.3390/en14082190

Academic Editor: Paweł Ocłoń

Received: 11 March 2021

Accepted: 12 April 2021

Published: 14 April 2021

Publisher's Note: MDPI stays neutral with regard to jurisdictional claims in published maps and institutional affiliations.

Copyright: (c) 2021 by the authors. Licensee MDPI, Basel, Switzerland. This article is an open access article distributed under the terms and conditions of the Creative Commons Attribution (CC BY) license (https:// creativecommons.org/licenses/by/ $4.0 /)$.

\begin{abstract}
In the process industry, a large amount of low-grade waste heat is discharged into the environment. Furthermore, district heating and cooling systems require considerable low-grade energy. The integration of the two systems has great significance for energy saving. Because the energy demand of consumers varies in periods, the design and operation of an industrial waste heat recovery system need to match with the fluctuations of district energy demand. However, the impact of the periodic changes on the integration schemes are not considered enough in existing research. In this study, a framework method for solving above problem is proposed. Industrial waste heat was integrated with a district heating and cooling system through a heat recovery loop. A three-step mathematical programming method was used in design and operation optimization for multiperiod integration. A case study was conducted, and the results show that the multiperiod optimization method can bring significant benefits to the system. By solving the mixed integer nonlinear programming model, the optimal operation plans of the integration in different periods can be obtained.
\end{abstract}

Keywords: waste heat; district heating and cooling; Heat Integration; multiperiod

\section{Introduction}

In the process industry, a large amount of waste heat usually exists. According to the different temperature levels, industrial waste heat can be divided into high-grade waste heat, medium-grade waste heat, and low-grade waste heat. Although there are no determinate boundaries between these three levels, it is acceptable that $650{ }^{\circ} \mathrm{C}$ and $230{ }^{\circ} \mathrm{C}$ are the dividing points [1]. As an effective method to reduce energy consumption, Heat Integration (HI) has been studied in depth in the past 40 years [2]. Such methods led to significant energy saving in the process industry around the world. The very first work involving HI was about heat exchanger network (HEN) synthesis. There are two mainstream methods for the design of HENs: pinch analysis (PA) and mathematical programming (MP). The former is based on thermodynamic principles and a graphical method [3], and the core of the latter is superstructure formulation, whereby the generalized superstructure [4] and the stage-wise superstructure are widely used [5]. In the process industry, high-grade and medium-grade waste heat can be effectively utilized by HENs. In addition, these two grades of waste heat can also be recovered for steam production by a waste heat boiler [6]. However, since heat sinks that need low-grade heat are rare, most low-grade waste has to discharge into the environment, causing serious energy waste [7]. In Europe, the amount of low-grade heat consumed by the chemical industry is up to 
1142 PJ every year, while $20-50 \%$ of it eventually becomes waste heat [8]; According to the estimation method of Fang et al. [9], $760 \mathrm{GJ}$ (a coal equivalent of nearly 260 million tons) of low-grade waste heat is lost in northern China every year.

Due to the above-mentioned reasons, effective utilization of low-grade waste heat has become a hotspot of research. Huang et al. [10] comprehensively summarized the technologies of low-grade waste heat utilization and classified these technologies into two categories: "heat upgrading" and "heat converting". The heat pump is the most popular "heat upgrading" technology. It takes high-grade energy as the driving force to convert low-grade heat into higher-grade heat. The "heat converting" technology can transform waste heat into mechanical work via thermodynamic cycles, and then electricity can be generated. There are three kinds of thermodynamic cycles that are usually used: organic Rankine cycle [11], Kalina cycle [12], and trilateral cycle [13]. Although these technologies have been researched intensively, the efficiency of low-grade waste heat utilization is still relatively low due to strict thermodynamic constraints.

In recent years, the integration of low-grade industrial waste heat into district heating and cooling (DHC) systems has become an attractive option. The DHC system delivers steam, hot water, or cold water from a central energy station to consumers via large-scale underground pipeline networks. DHC systems have developed in three generations. The media adopted for district heating $(\mathrm{DH})$ are steam, pressurized hot water, and atmospheric hot water. The method of district cooling (DC) has changed from transporting refrigerant to delivering cold water. Technologies such as natural cooling from lakes and absorption refrigeration have gradually been applied [14]. Therefore, more non-fossil-fuel energy sources can be integrated with the DHC systems in the future [15]. In the fourth-generation DHC system, utilization of low-grade industrial waste is more promising. The advantages of integrating low-grade industrial waste heat into the DHC system include improving energy efficiency, reducing fossil fuel combustion and greenhouse gas emissions, and saving a large amount of cooling water.

A number of studies were reported on utilizing industrial waste heat in DH systems. Tveit et al. [16] proposed a system framework for analyzing the integration of large-scale energy systems. They designed a flexible heat exchanger network with bypasses for the integration of four waste heat streams in a paper plant into a DH system. Their work was constructive in the early research on the integration of low-grade waste heat with DH systems, but they did not utilize waste heat for district cooling. Kapil et al. [17] proposed a method to identify the quantity and quality of waste heat from the total site that can be utilized in a DH system. Their method is based on economic benefit evaluation. They emphasized the influence of distance factors, operating conditions, and economic parameters on the economic benefits of the integration, but a concrete scheme for the integration including HEN was not designed. Fang et al. [9] combined the low-grade waste heat of two plants (a copper smeltery and a cement plant) for district heating. A total of $1896 \mathrm{~m}^{3} / \mathrm{h}$ of hot water at about $80^{\circ} \mathrm{C}$ can be obtained using their program of waste heat recovery. They discussed the three key issues related to using low-grade industrial waste heat for district heating in their subsequent work [18]: (1) "tangency technology" (a method similar to PA) was applied for the collection of multiple-grade waste heat sources; (2) technologies such as heat pump were suggested for long-distance delivery of waste heat; (3) a combined heat and power (CHP) plant was recommended for peak shaving. Wang et al. [19] improved the "tangency technology" using the exergy analysis method. Fitó et al. [20] discussed two design directions for the design of a waste heat recovery system for DH: energy-based and exergy-based optimal design. The methods of the above two studies can provide a clear energy target for integration, but the cost target and economic-related factors were not discussed enough. Recently, Khosravi et al. [21] suggested that the waste heat from data centers and fifth generation (5G) smart poles can be recovered for DH networks, and they confirmed the feasibility of utilizing low-grade waste heat in future urban smart thermal grids. 
Another effective method to utilize low-grade industrial waste heat is absorption refrigeration [12]. Through this technology, low-grade waste heat can be used in DC systems. A comprehensive review of this technology can be found in the work of Srikhirin et al. [22]. According to the total site Heat Integration (TSHI), Liew et al. [23] used low-grade waste heat in the site to drive the absorption chiller. Combined with the electric compression chiller, a lower cost was achieved in the case study.

Although many studies were presented on the utilization of low-grade industrial waste heat in DHC systems, almost all of them separately discussed waste heat utilization in DH systems or DC systems. In practice, both the heating demand and the cooling demand of consumers vary in different periods; thus, DH and DC systems should be considered simultaneously. Therefore, different heat recovery schemes for industries and different energy supply schemes in DHC systems are required in different periods. As the important methods of HI, PA and exergy analysis have been widely applied, but it is difficult for them to deal with complex problems involving multiple parameters and multiple dimensions. In cases with multiperiod $\mathrm{HI}$, the compatibility of operation schemes in different periods is important. Therefore, the above methods are not suitable. To solve the above problem, a three-step method based on mathematical programming is proposed in this paper. This method is an extension of our previous work in a conference paper [24]. In previous work, a scheme for DHC systems was not involved. By applying this method, the design and operation optimization of the heat recovery system and DHC can be obtained, and the operating parameters in each period can be determined.

\section{Problem Statement}

In the production area of a plant, there are several hot streams that need to be cooled. The low-grade waste heat of hot streams is originally discharged into the environment by cold utility. In this study, waste heat was integrated with the DHC system through a heat recovery loop (HRL), as shown in Figure 1. Hot water was chosen as the intermediate fluid. In order to establish this indirect HI, a small station for placing absorption chillers was built on the empty land near the plant. There was a long distance between the production area and the station. A pump was used to transport hot water in the HRL. This is called the "waste heat recovery (WHR) system" in this paper. After recovering the waste heat, hot water with a higher temperature is received, which can be directly used in district heating or to drive the operation of the absorption chiller. This is referred to as the "district energy supply (DES) system" in this paper.

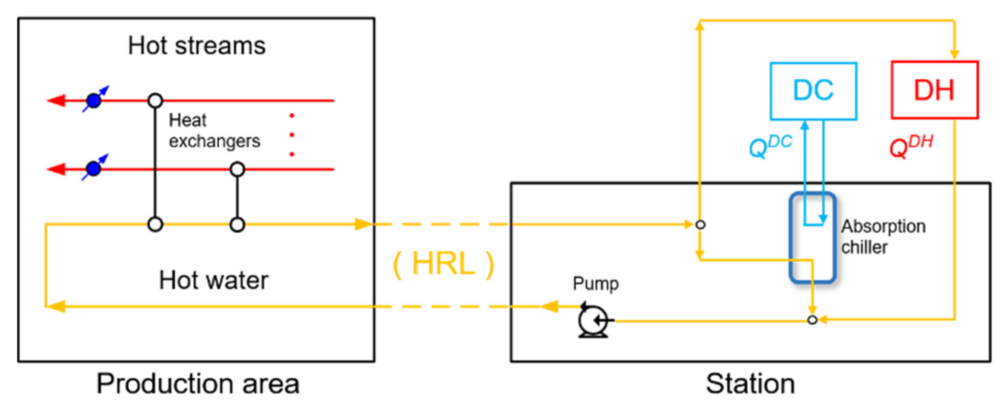

Figure 1. The indirect integration between waste heat and the district heating and cooling (DHC) system.

A number of consumers with heating or cooling demands exist in the region around the plant. Normally, the amount of waste heat from industries cannot satisfy the demands of all consumers; thus, the heating and cooling duties of the plant were determined in the first step of this study. In the WHR system, not all the waste heat is economic for recovery considering costs related to pumping, piping, and heat exchange. Only when the benefit is greater than the cost should the waste heat of the hot stream be recovered. Therefore, it is necessary to consider both cost and benefit in the objective function, as shown in Equation (1). By formulating and solving the mixed integer nonlinear programming 
(MINLP) model, a two-period HEN structure and the heating and cooling potential can be obtained. The mathematical model is introduced in Section 3.

$$
\min \left\{T A C=C^{c u}+C^{\text {exchanger }}+C^{\text {station }}+C^{\text {pipe,loop }}+C^{\text {pump }}-I^{D H C}\right\},
$$

where TAC is the total annual cost in the first step, $C^{c u}$ is the cost of cold utility that is still needed, $C^{\text {exchanger }}$ is the capital cost of heat exchangers installed to recover waste heat, $C^{\text {station }}$ is the capital cost of the station, including the cost of the absorption chiller, Cipe,loop and $C^{\text {pump }}$ are the capital cost of pipeline and the cost of pump in the HRL, And $I^{D H C}$ is the income of the plant by district heating and cooling. In all cases, capital costs are annualized.

Since each consumer has a different heating/cooling demand and distance to the plant, it is necessary to determine the suitable consumer for providing energy. Therefore, the second step of this study was to determine the match between industry and consumers. In a district energy system, the peak periods of heating and cooling are winter and summer. Some types of buildings (such as hospitals and data centers) have cooling demand throughout the year. Considering the above situation, the low-grade waste heat resource of the plant was used for district heating only in winter and district cooling throughout the year. It should be noted that the cooling demand is the highest in summer and lowest in winter, while the cooling demands in spring and autumn were assumed to be the same in this work.

There are two major costs in a DES system: the capital cost of pipelines between the energy station and consumers, and the capital cost of the absorption chiller. Both are directly related to the capacity of energy supply [25] (the cost of the absorption chiller is included in the cost of the station $C^{\text {station }}$. In order to determine the optimal scheme of energy supply, the objective function of the second step was to maximize the total profit of DES system, as shown in Equation (2). To avoid complexity in calculation, in this step, the operation in industry was not optimized.

$$
\min \left\{T A P=I^{D H C}-C^{p i p e, D H C}-C^{\text {station }}\right\},
$$

where TAP is the total annual profit of the DES system, and $C^{p i p e, D H C}$ is the capital cost of pipelines in the DHC system.

After the second step, the total heating or cooling capacity of the DES system in each period is known, but this does not mean that the operating scheme of the WHR system is fixed. Chang et al. [26] emphasized that there is a tradeoff in the HRL between the heat exchanger cost and the distance-related cost when the capacity of heat recovery is determined. Therefore, the third step of this study was to optimize the multiperiod operation schemes of the WHR system under a certain energy supply task. In this step, the energy supply constraint in each period was added into the model of the first step. The items $C^{\text {station }}$ and $I^{D H C}$ that were determined in the second step were deleted in the objective function, which is expressed by Equation (3).

$$
\min \left\{T A C^{\prime}=C^{c u}+C^{\text {exchanger }}+C^{\text {pipe,loop }}+C^{\text {pump }}\right\},
$$

where $T A C^{\prime}$ is the total annual cost in the third step.

In summary, this work was carried out in three steps: (1) determination of the heating and cooling potential of a plant; (2) determination of the regional energy supply objects in each period; (3) design and operation optimization of the multiperiod HRL under the definite energy supply task.

\section{Mathematical Formulation}

In this paper, hot streams of the plant are defined by index $i, I \in I, I=\{\mathrm{H} 1, \mathrm{H} 2, \ldots$, $\mathrm{Hm}\}$, periods are defined by index $s, s \in S, S=\{$ spring, summer, autumn, winter $\}$, and consumers are defined by index $j, j \in J, J=\{\mathrm{N} 1, \mathrm{~N} 2, \ldots, \mathrm{Nn}\}$. 


\subsection{The First Step}

In the DHC system, peak periods of heating and cooling are winter and summer. Therefore, for the convenience of expression, $s=$ winter represents the period with the maximum heating potential, and $s=$ summer represents the period with the maximum cooling potential.

\subsubsection{Model of Absorption Chiller}

Although dozens of compounds have been suggested as absorbents or refrigerants, the commonly used working fluid pairs of absorption refrigeration are still $\mathrm{H}_{2} \mathrm{O} / \mathrm{NH}_{3}$ and $\mathrm{LiBr} / \mathrm{H}_{2} \mathrm{O}$ [22]. Compared with $\mathrm{LiBr} / \mathrm{H}_{2} \mathrm{O}, \mathrm{H}_{2} \mathrm{O} / \mathrm{NH}_{3}$ requires a higher heat source temperature, while the double-effect and triple-effect absorption chillers require a higher heat source temperature than single-effect ones [27]. In order to utilize low-grade waste heat as much as possible, a single-effect $\mathrm{LiBr}-\mathrm{H}_{2} \mathrm{O}$ absorption chiller was selected in this study.

The COP (coefficient of performance) of the chiller is an important variable in absorption refrigeration. It is acceptable that the electricity consumed by the chiller can be ignored, whereby the cooling output of a single-effect $\mathrm{LiBr} / \mathrm{H}_{2} \mathrm{O}$ refrigerator is calculated using Equation (4) [28].

$$
Q_{s}^{\text {cold }}=\mathrm{COP}_{\mathrm{s}} \cdot Q_{\mathrm{s}}^{\text {recover }},
$$

where $Q_{s}^{\text {cold }}$ is the cooling output of the chiller, and $Q_{s}^{\text {recover }}$ is the capacity of the waste heat recovered. As mentioned, absorption refrigeration works in three periods: spring, summer, and autumn (only s = summer is involved in Section 3.1); thus, the subscript of the periodic element was added to the related symbols in this section.

Wang et al. [28] explored the variation in COP of a single-effect $\mathrm{LiBr} / \mathrm{H}_{2} \mathrm{O}$ refrigerator at three evaporator temperatures $\left(5^{\circ} \mathrm{C}, 8^{\circ} \mathrm{C}\right.$, and $\left.11^{\circ} \mathrm{C}\right)$. Pressurized hot water at $100-150^{\circ} \mathrm{C}$ was used as the heat source in their study. In this paper, the temperature of the evaporator was selected as $5{ }^{\circ} \mathrm{C}$. In this condition, there is a nonlinear relation between $C O P_{s}$ and the temperature of hot water entering the chiller $T_{s}^{w \text {, chiller, in }}$ [28]; accordingly, piecewise linearization should be used to describe this relationship, as expressed as Equation (5).

In mathematical programming, Equation (5) is replaced by Equations (6)-(12).

In the simulation conditions of Wang et al. [28], there is a one-to-one correspondence between $T_{s}^{w, \text { chiller, in }}$ and the temperature of hot water leaving the chiller $T_{s}^{w}$,chiller,out . According to their data, the relationship between $T_{s}^{w, \text { chiller, in }}$ and $T_{s}^{w, \text {,hiller,out }}$ is shown in Figure 2. It can be seen that there is an obvious linear relationship between $T_{s}^{w, \text {,chiller, in }}$ and $T_{s}^{w}$, chiller, out . Equation (13) can be obtained by linear fitting.

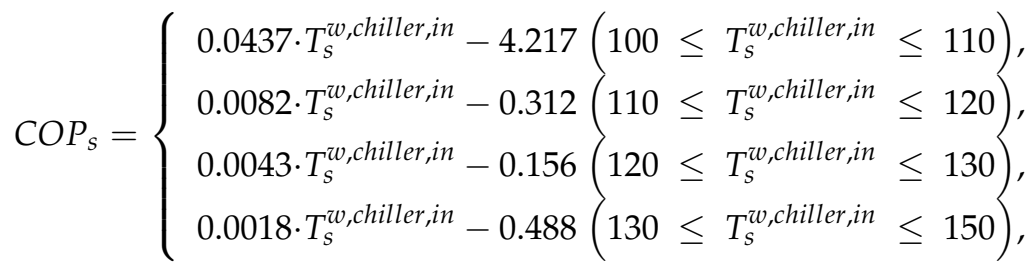

$$
\begin{aligned}
& y a_{s} \cdot 100 \leq T_{s}^{w, \text { chiller, }, \text { }, a} \leq y a_{s} \cdot 110, \\
& y b_{s} \cdot 110 \leq T_{s}^{w, \text { chiller, }, \mathrm{n}, b} \leq y b_{s} \cdot 120,
\end{aligned}
$$

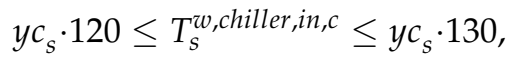

$$
\begin{aligned}
& y d_{s} \cdot 130 \leq T_{s}^{w, \text { chiller, }, n^{\prime} d} \leq y d_{s} \cdot 150, \\
& y a_{s}+y b_{s}+y c_{s}+y d_{s}=1, \\
& T_{s}^{w, \text { chiller, in }}=T_{s}^{w, \text { chiller, in, } a}+T_{s}^{w, \text {,hiller, in, } b}+T_{s}^{w, \text { chiller, in, } c}+T_{s}^{w, \text { chiller, in, } d,},
\end{aligned}
$$




$$
\begin{aligned}
& \operatorname{COP}_{s}=\left(0.0437 \cdot T_{s}^{w, \text { chiller, }, \text { }, a}-y a_{s} \cdot 4.217\right)+\left(0.0082 \cdot T_{s}^{w, \text { chiller, }, \text { }, b}-y b_{s} \cdot 0.312\right)+ \\
& \left(0.0043 \cdot T_{s}^{w, \text {,hiller, }, \text { }, c}-y c_{s} \cdot 0.156\right)+\left(0.0018 \cdot T_{s}^{w, \text { chiller, }, i n, d}-y d_{s} \cdot 0.488\right),
\end{aligned}
$$

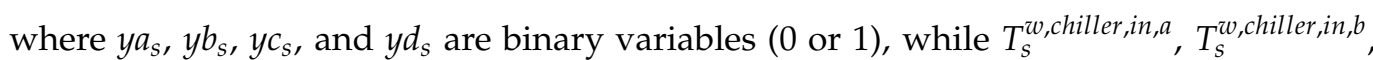

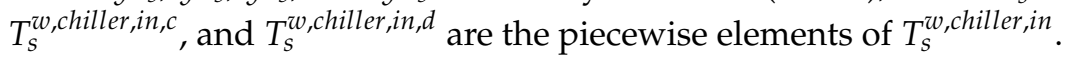

$$
T_{s}^{w, \text { chiller,out }}=0.426 \cdot T_{S}^{w, \text { chiller, in }}+52.8 \text {. }
$$

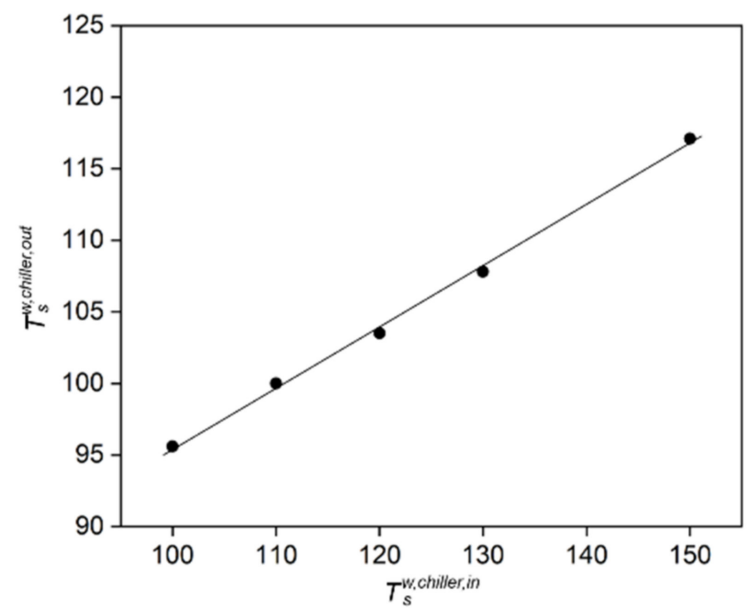

Figure 2. The relationship between $T_{s}^{w, \text { chiller, in }}$ and $T_{S}^{w, \text { chiller,out }}$ [28].

The investment of the station including the capital cost of the absorption chiller is calculated using Equation (14).

$$
C^{\text {station }}=A f \cdot\left(b_{1}+b_{2} \cdot Q_{s}^{\text {cold }}\right)(s=\text { summer }),
$$

where $A f$ is the annual factor, and $b_{1}$ and $b_{2}$ are the parameters of the cost of the small station.

\subsubsection{Model of HEN}

In the WHR system, the stage-wise superstructure [5] is adopted to formulate the heat exchanger network, which is shown in Figure 3. The parameters $T_{i}^{h s, \text { in }}, T_{h s, o u t} I$, and $F_{i}^{h s}$ are the initial temperature, target temperature, and flow capacity of hot stream $i$, respectively. The variables $T_{s}^{w, H E N, \text { in }}, T_{s}^{w, H E N, \text { out }}$, and $m_{s}^{w, \text { total }}$ are the inlet temperature, outlet temperature, and mass flow rate of hot water in period s. $m_{i, k, s}^{w, s p l i t}$ and $q_{i, k, s}$ represent the mass flow rate of hot water and the heat load of exchanger for hot stream $i$ at stage $k$ in period s. $T_{i, k, s}^{h s}$ and $T_{k, s}^{w, H E N}$ represent the temperature of hot stream $i$ and hot water at hot end of stage $k . q_{i, s}^{c u}$ is the heat load of cooler between hot stream $i$ and cold utility.

The inlet and outlet temperatures of hot streams and hot water in HEN are defined by Equations (15)-(17).

$$
\begin{gathered}
T_{i, 1, s}^{h s}=T_{i}^{h s, i n} . \\
T_{1, s}^{w, H E N}=T_{s}^{w, H E N, \text { out }} . \\
T_{\mathrm{NT}+1, \mathrm{~s}}^{w, H E N}=T_{s}^{w, H E N, \text { in }} .
\end{gathered}
$$

In current $\mathrm{DH}$ systems, the temperature of atmospheric hot water sent to consumers $\left(T_{s}^{w, H E N, \text { out }}\right)$ is generally required to be higher than $70^{\circ} \mathrm{C}[14]$. The temperature of water sent back to the station $\left(T_{s}^{w, H E N, i n}\right)$ is always not lower than $40^{\circ} \mathrm{C}$ [15]. In order to reduce the solution difficulty, the latter temperature was fixed to be $40{ }^{\circ} \mathrm{C}$ rather than being a 
variable in this work. Therefore, the constraints for the temperature of hot water in the WHR system in winter are expressed by Equations (18) and (19).

$$
\begin{gathered}
\left.70 \leq T_{s}^{w, H E N, \text { out }} \leq 100 \text { ( } s=\text { winter }\right) . \\
\left.T_{s}^{w, H E N, \text { in }}=40 \text { ( } s=\text { winter }\right) .
\end{gathered}
$$

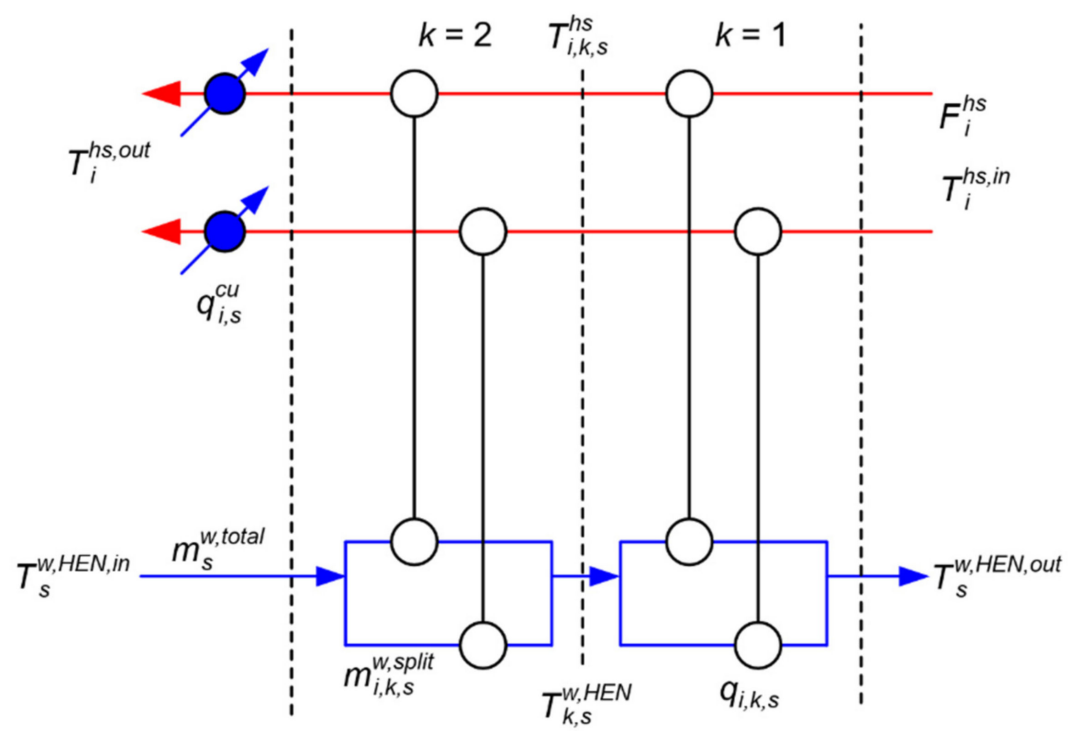

Figure 3. The stage-wise superstructure.

In summer, the inlet and outlet temperature of hot water in the HEN are equal to the temperature leaving and entering the absorption chiller; thus, Equation (20) emerges on the basis of Equation (13).

$$
\left.T_{s}^{w, H E N, \text { in }}=0.426 \cdot T_{s}^{w, H E N, \text { out }}+52.8 \text { (s= summer }\right) .
$$

The total capacity of waste heat recovered is calculated by Equation (21). $c p^{w}$ represents the specific heat capacity of water.

$$
Q_{s}^{\text {recover }}=c p^{w} \cdot m_{s}^{w, \text { total }} \cdot\left(T_{s}^{w, H E N, \text { out }}-T_{s}^{w, H E N, \text { in }}\right) .
$$

Energy and mass balance constraints for hot water and hot streams are expressed by Equations (22)-(27).

$$
\begin{gathered}
q_{i, k, s}=F_{i}^{h s} \cdot\left(T_{i, k, s}^{h s}-T_{i, k+1, s}^{h s}\right) . \\
q_{i, k, s}=c p^{w} \cdot m_{i, k, s}^{w, s p l i t} \cdot\left(T_{k, s}^{w, H E N}-T_{k+1, s}^{w, H E N}\right) . \\
m_{s}^{w, \text { total }}=\Sigma_{i} m_{i, k, s}^{w, s p l i t} \cdot \\
\Sigma_{i} q_{i, k, s}=c p^{w} \cdot m_{s}^{w, \text { total }} \cdot\left(T_{k, s}^{w, H E N}-T_{k+1, s}^{w, H E N}\right) . \\
q_{i, s}^{c u}=F_{i}^{h s} \cdot\left(T_{N T+1, s}^{h s}-T_{i}^{h s, o u t}\right) . \\
F_{i}^{h s} \cdot\left(T_{i}^{h s, i n}-T_{i}^{h s, o u t}\right)=\Sigma_{k} q_{i, k, s}+q_{i, s}^{c u} .
\end{gathered}
$$

The Big-M constraints for heat loads and temperature approaches are used to determine the existence of heat exchangers, which are expressed by Equations (28)-(30).

$$
\begin{gathered}
q_{i, k, s} \leq z_{i, k} \cdot q_{i}^{h s} \\
d t_{i, k, s} \leq T_{i, k, s}^{h s}-T_{k, s}^{w, H E N}+\left(1-z_{i, k}\right) \cdot \Gamma,
\end{gathered}
$$




$$
d t_{i, k+1, s} \leq T_{i, k+1, s}^{h s}-T_{k+1, s}^{w, H E N}+\left(1-z_{i, k}\right) \cdot \Gamma,
$$

where $z_{i, k}$ is the binary variable to indicate whether the heat exchanger between hot water and hot stream $i$ at stage $k$ exists. $q_{i}^{h s}$ is the total heat load of hot stream $i . d t_{i, k, s}$ is the temperature approach between hot stream $i$ and hot water at hot end of stage $k$ in period s. The parameter $\Gamma$ is the upper bound for temperature difference, which is $250{ }^{\circ} \mathrm{C}$ in this paper. If the heat exchanger exists, the binary variable $z_{i, k}$ is equal to 1 ; if the heat exchanger does not exist, $z_{i, k}$ can be 0 or 1 in Equations (28)-(30). In order to minimize the cost of heat exchangers, $z_{i, k}$ is forced to be equal to 0 by objective function.

The temperature approaches must be greater than the minimum temperature difference $\Delta T_{\min }$ in order to meet the requirement for heat transfer. This relationship is shown by Equation (31).

$$
d t_{i, k, s} \geq \Delta T_{\min } .
$$

Equation (32) is employed to calculate the heat transfer area needed for hot water to recover the heat of hot stream $i$ at stage $k$ in period $s\left(A_{i, k, s}^{\text {period }}\right)$.

$$
A_{i, k, s}^{\text {period }}=q_{i, k, s} \cdot\left(1 / h^{w}+1 / h_{i}^{h s}\right) / L M T D_{i, k, s}
$$

where $L M T D_{i, k, s}$ is the logarithmic mean temperature difference of this heat exchanger. $h^{w}$ and $h_{i}^{h s}$ are the film heat transfer coefficients of hot water and hot stream $i$.

In order to reduce the solution difficulty, $L M T D_{i, k, s}$ is calculated using the Chen approximation [29], which is expressed by Equation (33).

$$
\operatorname{LMTD}_{i, k, s}=\left[d t_{i, k, s} \cdot d t_{i, k+1, s} \cdot\left(d t_{i, k, s}+d t_{i, k+1, s}\right) / 2\right]^{1 / 3} .
$$

In multiperiod HENs, the design area of exchanger $\left(A_{i, k}^{\text {design }}\right)$ is the maximum area needed in all periods [30], which is expressed by Equation (34).

$$
A_{i, k}^{\text {design }} \geq A_{i, k, s}^{\text {period }}
$$

Equations (35) and (36) are used to calculate the cost of cold utility and the capital cost of heat exchangers, respectively.

$$
\begin{gathered}
C^{c u}=\Sigma_{i} \Sigma_{s} u^{c u} \cdot\left(t_{s}^{\text {period }} / t^{\text {total }}\right) \cdot q_{i, s^{\prime}}^{c u} \\
C^{\text {exchanger }}=A f \cdot\left[\alpha \cdot \Sigma_{i} \Sigma_{k} z_{i, k}+\beta \cdot \Sigma_{i} \Sigma_{k} A_{i, k}^{\text {design }}\right] \gamma,
\end{gathered}
$$

where $u^{c u}$ is the unit cost of cold utility. $t_{s}^{\text {period }}$ and $t^{\text {total }}$ are the time of period $s$ and total year. $\alpha, \beta$, and $\gamma$ are the cost parameters of the heat exchanger.

\subsubsection{Model of Pipeline}

There are two types of pipelines in the HRL: a long pipeline between production area and station and short pipelines in the production area. This work only considers the long pipeline, while short pipelines are ignored. Peters et al. [31] provided an equation for designing the inner diameter of the pipeline using an appropriate velocity. However, the flow rate of hot water varies in different periods, resulting in a variable velocity. In this study, the inner diameter of the pipeline takes the maximum value in each period. It is indicated that hot water flows at the velocity recommended by Peters et al. only in the period with the largest flow rate [31]. In other periods, hot water flows more slowly. Because of the high temperature, desalinated water should be used as the intermediate fluid; hence, the situation of fouling is ignored in this study. Therefore, the inner diameter 
$\left(D_{\text {in }}\right)$ of the pipeline between production area and station is expressed by Equation (37) according to the method of Peters et al. [31].

$$
D_{\text {in }}=0.363 \cdot\left(m_{s}^{w, t o t a l} / \rho_{s}\right)^{0.45} \cdot \rho_{s}^{0.13},
$$

where $\rho_{s}$ is the density of hot water. It should be declared that the densities of atmospheric water and pressurized water are different.

Because the pressurized hot water is used for absorption refrigeration, the schedule 80 steel pipe is employed in HRL. The cost of the pipeline per unit length in HRL $\left(P c u l^{l o o p}\right)$ was calculated using the method of Stijepovic et al. [32], which is shown by Equations (38)-(40).

$$
\begin{gathered}
D_{\text {out }}=1.101 \cdot D_{\text {in }}+0.006349 . \\
W t=1330 \cdot D_{\text {in }}{ }^{2}+75.18 \cdot D_{\text {in }}+0.9268 . \\
\text { Pcul }^{\text {loop }}=a_{1} \cdot W t+a_{2} \cdot D_{\text {out }}{ }^{0.48}+a_{3}+a_{4} \cdot D_{\text {out }} .
\end{gathered}
$$

The total cost of the pipeline in the HRL is calculated using Equation (41). $L^{\text {loop }}$ is the distance between station and production area.

$$
C^{\text {pipe,loop }}=A f \cdot 2 \cdot L^{\text {loop }} \cdot \text { Pcul loop }
$$

\subsubsection{Model of Pump}

In the HRL, the pressure drop of hot water should be overcome by the pump. The total pressure drop of hot water $\Delta p_{s}^{\text {total }}$ is expressed in Equation (42).

$$
\Delta p_{s}^{\text {total }}=\Delta p_{s}^{\text {distance }}+\Delta p_{s}^{H E N},
$$

where $\Delta p_{s}^{\text {distance }}$ and $\Delta p_{s}^{H E N}$ are the pressure drop of hot water in the long pipeline and HEN in period $s$.

$\Delta p_{s}^{\text {distance }}$ is calculated using the Fanning formula. The detailed process of calculation is not introduced here; a calculation case can be found in [26].

The pressure drop of hot water in the tube side of each heat exchanger $\left(\Delta p_{i, k, s}^{\text {tube }}\right)$ is calculated using the method of Soltani et al. [33], which is shown by Equations (43) and (44).

$$
\begin{gathered}
K t_{i, k, s}=\left(\Phi^{4.5} \cdot d i^{0.5} \cdot \mu_{s}^{11 / 6}\right) \cdot(d i / d e) /\left[0.023^{2.5} \cdot m_{i, k, s}^{w, s p l i t} \cdot \rho_{s} \cdot k^{7 / 3} \cdot\left(c p^{w}\right)^{7 / 6}\right] . \\
\Delta p_{i, k, s}^{\text {tube }}=K t_{i, k, s} \cdot A_{i, k, s}^{\text {period }} \cdot\left(h^{w}\right)^{3.5} .
\end{gathered}
$$

In the HEN based on the stage-wise superstructure, the pipes of hot water are in a series-parallel structure, whereas stages are connected in series. Therefore, the total pressure drop of hot water in the HEN is equal to the sum of pressure drop in each stage $\left(\Delta p_{k, s}^{\text {stage }}\right)$; this relationship is shown in Equation (45).

$$
\Delta p_{s}^{H E N}=\Sigma_{k} \Delta p_{k, s}^{\text {stage }} .
$$

According to the principle of fluid flow, the pressure drops of fluid on branches are equal in a stable condition. Therefore, the pressure drop of hot water at a stage is equal to the maximum pressure drop of each branch, as shown in Equation (46).

$$
\Delta p_{k, s}^{\text {stage }} \geq \Sigma_{k} \Delta p_{i, k, s}^{\text {tube }}
$$

The power of pump in each period $\left(P_{s}^{\text {period }}\right)$ and the rated power of pump $\left(P^{\text {rate }}\right)$ are expressed by Equations (47) and (48), respectively.

$$
P_{s}^{\text {period }}=\left(m_{s}^{w, \text { total }} \cdot \Delta p_{s}^{\text {total }}\right) / \rho_{s} .
$$




$$
P^{\text {rate }} \geq P_{S}^{\text {period }}
$$

The cost of pump $C^{\text {pump }}$ is equal to the sum of capital cost and operation cost, which are calculated using Equations (50) and (51), respectively.

$$
\begin{gathered}
C^{\text {pump }}=C^{\text {pump }, \text { cap }}+C^{\text {pump }, \text { op },} \\
C^{\text {pump,cap }}=A f \cdot\left[c_{1}+c_{2} \cdot\left(P^{\text {rate }}\right)^{c 3}\right], \\
C^{\text {pump }, \text { cap }}=u^{e} \cdot \Sigma_{s}\left(P_{S}^{\text {period }} \cdot t_{S}^{\text {period }}\right) /(1000 \cdot \eta),
\end{gathered}
$$

where $c_{1}, c_{2}$, and $c_{3}$ are the parameters of capital cost of the pump, $u^{e}$ is the unit price of electricity, and $\eta$ is the efficiency of pump.

\subsubsection{Calculation of Income}

The maximum heating and cooling potentials $\left(Q^{D H, \text { max }}\right.$ and $\left.Q^{D C, \text { max }}\right)$ are represented by Equations (52) and (53). The total income of the plant in these two periods is calculated by Equation (54). $u^{D C}$ and $u^{D H}$ are the unit prices of heating and cooling respectively.

$$
\begin{gathered}
Q^{D H, \text { max }}=Q_{s=\text { winter }}^{\text {recover }} \\
Q^{D C, \text { max }}=Q_{s=\text { summer }}^{\text {recover }} \\
I^{D H C}=\left(u^{D C} \cdot Q^{D C, \text { max }} \cdot t_{s=\text { summer }}^{\text {period }}\right)+\left(u^{D H} \cdot Q^{D H, \text { max }} \cdot t_{s=\text { winter }}^{\text {period }}\right) .
\end{gathered}
$$

\subsection{The Second Step}

Based on the heating and cooling potential of the plant obtained in the first step, the classic "knapsack problem" model in integer programming was used to determine the actual energy supply task in each period. The "knapsack problem" can be expressed as follows: a traveler has to choose among items with different weights and values, and then put the selected items into a knapsack with a certain capacity, where the maximum total value of selected items is expected. In this study, the plant is the "knapsack", and consumers are the "items" to be selected.

In the second step, all the period-related elements were included. In a DHC system, the loss of heat and cold are often more than $10 \%$ in the distribution network [15]. The difference between the actual capacity of heat/cold supplied to consumer $j$ from plant $\left(E_{j, s}^{\text {supply }}\right)$ and the demand of consumer $j\left(E_{j, s}^{\text {need }}\right)$ cannot be ignored. The loss of energy per unit distance in DHC system can be taken as $1 \% / \mathrm{km}$ [17]. Equation (55) is used to express the relationship between $E_{j, s}^{\text {supply }}$ and $E_{j, s}^{\text {need }} . L_{j}^{\text {consumer }}$ is the distance between the plant and consumer $j$.

$$
E_{j, s}^{\text {supply }}=E_{j, s}^{\text {need }} /\left[0.99^{\left(\text {Lonsumer }_{j}^{\text {con }} / 1000\right)}\right] .
$$

According to the "knapsack problem" model, the binary variable $y_{j, s}^{\text {supply }}$ is used for the selection of consumers, which is shown in Equation (56).

$$
\Sigma_{j} y_{j, s}^{\text {supply }} \cdot E_{j, s}^{\text {supply }} \leq\left\{\begin{array}{c}
Q^{D C, \max }(s=\text { spring, summer, autumn }) \\
Q^{D C, \max }(s=\text { winter }) .
\end{array}\right.
$$

In a DHC system, the temperature difference between supply and return of water in the DC system is much smaller than that in the DH system, which means that the diameters of pipelines in the DC system is often significantly larger than that in the DH system [15]. Therefore, the pipelines cannot be shared by these two systems. However, Best et al. [34] proposed that the flow rate of water transported by the pipeline with a certain diameter can be within a range in a DHC system; that is, the minimum flow rate should be greater than 0.475 times the maximum flow rate. This recommendation makes it possible to combine the pipeline for district cooling in spring/autumn and summer. In this study, the supply and 
return temperature of cold water in DC system were set to $7^{\circ} \mathrm{C}$ and $12{ }^{\circ} \mathrm{C}$. Therefore, the flow rate of cold water supplied to each consumer is proportional to its demand of cooling. When the demands of a consumer in periods are given, it can be known whether it is feasible that the DC pipeline can be shared in spring/autumn and summer. This possibility is expressed by the binary parameter $y_{j}^{\text {combine }}$, which is shown in Equation (57).

$$
y_{j}^{\text {combine }}=\left\{\begin{array}{l}
0\left(E_{j, s=\text { spring }}^{\text {supply }} \leq 0.475 \cdot E_{j, s=\text { spring }}^{\text {supply }}=\text { spring }\right), \\
1\left(E_{j, s=\text { spring }}^{\text {supply }} \geq 0.475 \cdot E_{j, s=\text { spring }}^{\text {supply }}=\text { spring }\right) .
\end{array}\right.
$$

When consumer $j$ is cooled by the plant in spring/autumn, if it is also cooled in summer, and the condition $y_{j}^{\text {combine }}=1$ is satisfied, the pipeline of consumer $j$ can be shared in spring, summer, and autumn. Therefore, on the condition that the combination of DC pipeline is considered, the total capital cost of pipelines in the DHC system $C^{\text {pipe, } D H C}$ can be calculated using Equations (58)-(61).

$$
\begin{gathered}
C^{\text {pipe }, D H C}=C^{\text {pipe }, D H C, \text { wiNTer }}+C^{\text {pipe }, D H C, \text { summer }}+C^{\text {pipe, DHC, spring },} \\
C^{\text {pipe }, D H C, \text { winter }}=\Sigma_{j} y_{j, s=\text { winter }}^{\text {supply }} \cdot\left(L_{j}^{\text {consumer }} \cdot P c u l_{j, s=\text { winter }}^{D H C}\right), \\
C^{\text {pipe }, D H C, \text { summer }}=\Sigma_{j} y_{j, s=\text { summer }}^{\text {supply }} \cdot\left(L_{j}^{\text {consumer }} \cdot P c u l_{j, s=\text { summer }}^{D H C}\right), \\
C^{\text {pipe }, D H C, \text { spring }}=\Sigma_{j} y_{j, s=\text { spring }}^{\text {supply }} \cdot\left(1-y_{j}^{\text {combine }} \cdot y_{j, s}^{\text {supply }}\right) \cdot\left(L_{j}^{\text {consumer }} \cdot P c u l_{j, s=\text { spring }}^{D H C}\right),
\end{gathered}
$$

where $P c u l_{j, s}^{D H C}$ is the cost of the pipeline per unit length from the plant to consumer $j$ in period $s$.

The calculation methods for the cost of pipeline in the DHC system and in the HRL are different. Best et al. [34] provided a range of flow rates of water corresponding to a series of inner pipeline diameters in a DHC system. The inner diameter is the unique variable of the cost of pipeline per unit length $\left(P_{c u l} l_{j, s}^{D H C}\right)$, while the relationship between $P c u l$ DHC and $E_{j, s}^{s u p p l y}$ can be obtained indirectly according to the data of Best et al. [34]. It should be explained that, because the supply and return temperatures of cold water in a DC system are fixed, the mass flow rate of cold water supplied to a certain consumer is constant. The maximum flow rate in the range can be adopted to determine the relationship between $P c u l l_{j, s}^{D H C}$ and $E_{j, s}^{s u p p l y}$. However, the supply temperature of hot water in a DH system (namely, $T_{S}^{w, H E N, o u t}$ in this paper) is a variable to be optimized that ranges from $70{ }^{\circ} \mathrm{C}$ to $100{ }^{\circ} \mathrm{C}$. Because the return temperature was set to $40{ }^{\circ} \mathrm{C}$, the difference between the supply and return temperatures of hot water ranges from $30^{\circ} \mathrm{C}$ to $60^{\circ} \mathrm{C}$. It is indicated that the maximum flow rate of hot water can reach twice the minimum value in conditions of a certain heating capacity. Therefore, the average flow rate of the range should be adopted to determine the relationship between $P c u l_{j, s}^{D H C}$ and $E_{j, s}^{s u p p l y}$ for the DH system. Since the data provided by Best et al. [34] are in a large range, the fitting range should be narrowed when $E_{j, s}^{\text {supply }}$ is known in order to reduce the error of the relationship as much as possible. In Section 5, an equation of the relationship between $P c u l_{j, s}^{D H C}$ and $E_{j, s}^{\text {supply }}$ is provided in a case study.

In the second step, the optimal scheme for the DES system in each period can be obtained. The total capacity of energy supplied ( $\left.E_{S}^{t o t a l}\right)$ is expressed by Equation (62).

$$
E_{s}^{\text {total }}=\Sigma_{j} y_{j, s}^{\text {supply }} \cdot E_{j, s}^{\text {supply }}
$$


The total income of the plant in this step is calculated using Equation (63).

$$
\begin{gathered}
I^{D H C}=u^{D C} \cdot\left(\Sigma_{j} y_{j, s=\text { spring }}^{\text {supply }} \cdot E_{j, s=\text { spring }}^{\text {need }}\right) \cdot t_{s=\text { spring }}^{\text {period }}+u^{D C} \cdot\left(\Sigma_{j} y_{j, s=\text { summer }}^{\text {supply }} \cdot E_{j, s=\text { summer }}^{\text {need }}\right) \cdot t_{s=\text { summer }}^{\text {period }} \\
\quad+u^{D C} \cdot\left(\Sigma_{j} y_{j, s=\text { autumn }}^{\text {supply }} \cdot E_{j, s=\text { autumn }}^{\text {need }}\right) \cdot t_{s=\text { autumn }}^{\text {period }}+u^{D H} \cdot\left(\Sigma_{j} y_{j, s=\text { winter }}^{\text {supply }} \cdot E_{j, s=\text { winter }}^{\text {need }}\right) \cdot t_{s=\text { winter }}^{\text {period }}
\end{gathered}
$$

\subsection{The Third Step}

The set of periods in the third step is as follows: $S=$ sspring, summer, autumn, winter . The constraint of the energy supply task of plant in each period obtained in the second step is added into the model, which is shown by Equation (64); then, the optimization of the operation scheme for the WHR system can be carried out. The rest of the model is the same as the first step.

$$
E_{s}^{\text {total }}=\left\{\begin{array}{c}
C O P_{s} \cdot Q_{s}^{\text {recover }}(s=\text { spring, summer, autumn }), \\
Q_{s}^{\text {recover }}(s=\text { winter }) .
\end{array}\right.
$$

\section{Solution Strategy}

The MINLP model in this paper is very complex, and many nonlinear terms are involved in the model; therefore, it is very difficult to obtain a good solution. In order to overcome such a problem, two methods are adopted in this paper.

First, the linearization of the cost of pipeline in the HRL is employed. It can be found that the inner diameter of pipeline Din is the unique variable for Pcul loop. Hence, the linear fitting of Pcul loop can be performed taking Din as the variable, and the nonlinear Equations (38)-(40) can be replaced by a linear equation to reduce the complexity of calculation.

Second, because the cooling capacity in spring and autumn is less than that in summer, the solution process of the third step can be divided into two sub-steps. Only summer and winter are involved in the first sub-step. In the second sub-step, according to the results obtained in the first sub-step, the upper bound of the heat exchanger areas and the upper bound of the pump rated power are given. The optimization of schemes in spring and autumn can be conducted individually. In the objective function of the second sub-step, the capital costs of heat exchangers and pump are not involved.

The solution of the MINLP model can be made much easier by these two methods.

\section{Case Study}

\subsection{Data}

In this case, there are 10 hot streams in the plant; the data are shown in Table 1.

Table 1. The data of hot streams.

\begin{tabular}{cccccc}
\hline $\boldsymbol{i}$ & $\boldsymbol{T}_{\boldsymbol{i}}^{h \boldsymbol{h}, \text { in }}\left({ }^{\circ} \mathbf{C}\right)$ & $\boldsymbol{T}_{\boldsymbol{i}}^{h s, \text { out }}\left({ }^{\circ} \mathbf{C}\right)$ & $\boldsymbol{F}_{\boldsymbol{i}}^{h \boldsymbol{s}}\left(\mathbf{k W} /{ }^{\circ} \mathbf{C}\right)$ & $\boldsymbol{q}_{\boldsymbol{i}}^{h s}(\mathbf{k W})$ & $\boldsymbol{h}_{\boldsymbol{i}}^{h s}\left(\mathbf{k W} / \mathbf{m}^{\mathbf{2}} \cdot{ }^{\circ} \mathbf{K}\right)$ \\
\hline H1 & 140 & 75 & 24 & 1560 & 2 \\
H2 & 186 & 68 & 34 & 4012 & 2 \\
H3 & 200 & 105 & 38 & 3610 & 2 \\
H4 & 144 & 40 & 30 & 3120 & 2 \\
H5 & 175 & 93 & 30 & 2460 & 2 \\
H6 & 160 & 42 & 40 & 4720 & 2 \\
H7 & 153 & 56 & 32 & 3104 & 2 \\
H8 & 130 & 50 & 35 & 2800 & 2 \\
H9 & 100 & 80 & 54 & 1080 & 2 \\
H10 & 95 & 35 & 26 & 1560 &
\end{tabular}

There are eight consumers in the region; the data are shown in Table 2.

The time of each period and the physical properties of water in each period are presented in Table 3.

Other physical parameters and economic parameters are listed in Tables 4 and 5. 
Table 2. The data of consumers.

\begin{tabular}{|c|c|c|c|c|c|c|}
\hline \multirow{2}{*}{$j$} & \multirow{2}{*}{$L_{j}^{u s e r}(\mathrm{~m})$} & \multicolumn{4}{|c|}{$E_{j, s}^{n e e d}(\mathbf{k W})$} & \multirow{2}{*}{$y_{j}^{\text {combine }}$} \\
\hline & & $s=$ Spring & $s=$ Summer & $s=$ Autumn & $s=$ Winter & \\
\hline N1 & 5200 & 0 & 0 & 0 & 4000 & 0 \\
\hline N2 & 6300 & 1000 & 2500 & 1000 & 2000 & 0 \\
\hline N3 & 7000 & 0 & 1800 & 0 & 3000 & 0 \\
\hline N4 & 7900 & 0 & 0 & 0 & 7000 & 0 \\
\hline N5 & 9500 & 2000 & 4000 & 2000 & 5000 & 1 \\
\hline N6 & 10,400 & 1800 & 2000 & 1800 & 6000 & 1 \\
\hline N7 & 11,000 & 0 & 0 & 0 & 8000 & 0 \\
\hline N8 & 11,800 & 0 & 3500 & 0 & 5000 & 0 \\
\hline
\end{tabular}

Table 3. The period-related data.

\begin{tabular}{cccc}
\hline $\boldsymbol{s}$ & $\boldsymbol{t}_{\boldsymbol{s}}^{\text {period }} \mathbf{( \mathbf { h } )}$ & $\boldsymbol{\rho}_{\boldsymbol{s}} \mathbf{( \mathbf { k g } / \mathbf { m } ^ { 3 } )}$ & $\mu_{\boldsymbol{s}}(\mathbf{m P a} \cdot \mathbf{s})$ \\
\hline spring & 1500 & 945 & 0.242 \\
summer & 2880 & 945 & 0.242 \\
autumn & 1500 & 945 & 0.242 \\
winter & 2880 & 980 & 0.430 \\
\hline
\end{tabular}

Table 4. Physical parameters of the case.

\begin{tabular}{ccc}
\hline Items & Remarks & Data \\
\hline$\Delta T_{\text {min }}$ & Minimum approach temperature difference & $10{ }^{\circ} \mathrm{C}$ \\
$h^{w}$ & Film heat transfer coefficient of hot water & $1.5 \mathrm{~kW} / \mathrm{m}^{2}{ }^{\circ} \mathrm{C}$ \\
$c p^{w}$ & Specific heat capacity of hot water & $4.2 \mathrm{~kJ} / \mathrm{kg}^{\circ} \mathrm{C}$ \\
$\Phi$ & Viscosity correction factor & 1.05 \\
$k$ & Conductivity & $0.6 \mathrm{~W} / \mathrm{m}{ }^{\circ} \mathrm{C}$ \\
$d i$ & Tube internal diameter of heat exchanger & $15.4 \mathrm{~mm}$ \\
$d e$ & Tube external diameter of heat exchanger & $19.1 \mathrm{~mm}$ \\
$L^{\text {loop }}$ & Distance between station and production area & $400 \mathrm{~m}$ \\
$\eta$ & Pump efficiency & 0.7 \\
\hline
\end{tabular}

Table 5. Economic parameters of the case.

\begin{tabular}{ccc}
\hline Items & Remarks & Data \\
\hline$A f$ & Annualized factor [26] & 0.264 \\
\hline$\alpha$ & Cost parameters of heat & $11,000 \$$ \\
$\beta$ & exchanger [32] & $150 \$ / \mathrm{m}^{2}$ \\
$\gamma$ & Cost parameters of cooling & 1 \\
\hline$b_{1}$ & station [25] & $400,000 \$$ \\
$b_{2}$ & & $400 \$ / \mathrm{kW}$ \\
\hline$a_{1}$ & Cost parameters of pipe [32] & $0.82 \$ / \mathrm{kg}$ \\
$a_{2}$ & & $185 \$ / \mathrm{m}^{1.48}$ \\
$a_{3}$ & $6.8 \$ / \mathrm{m}$ \\
$a_{4}$ & Cost parameters of pump [35] & $295 \$ / \mathrm{m}^{2}$ \\
\hline$c_{1}$ & & $8600 \$$ \\
$c_{2}$ & Unit price of cold utility [26] & 0.2 \\
$c_{3}$ & Unit price of electricity [26] & $15 \$ / \mathrm{kW} \cdot \mathrm{y}$ \\
$u^{c u}$ & Unit price of cooling [15] & $0.1 \$ / \mathrm{kW} \cdot \mathrm{h}$ \\
$u^{e}$ & Unit price of heating [15] & $60 \$ / \mathrm{MW} \cdot \mathrm{h}$ \\
$u^{D C}$ & & $100 \$ / \mathrm{MW} \cdot \mathrm{h}$ \\
$u^{D H}$ & &
\end{tabular}


According to the demand information of consumers in this case, Equation (65) can be obtained by fitting the data provided by Best et al. [34].

$$
\operatorname{Pcul}_{j, s}^{\text {DHC }}=\left\{\begin{aligned}
-0.4213 & \cdot\left(\frac{E_{j, s}^{\text {supply }}}{1000}\right)^{2}+8.752 \cdot\left(\frac{E_{j, s}^{\text {supply }}}{1000}\right)+164.7(s=\text { spring, summer, autumn }), \\
& \left.-0.1356 \cdot\left(\frac{E_{j, s}^{\text {supply }}}{1000}\right)^{2}+3.519 \cdot\left(\frac{E_{j, s}^{\text {supply }}}{1000}\right)+156.4 \text { (s = winter }\right) .
\end{aligned}\right.
$$

According to the first solution strategy, the approximate linear relationship between Pculloop and Din can be obtained, as shown in Equation (66). Equations (37)-(40) can be replaced by Equation (66).

$$
\text { Pcul }^{\text {loop }}=1410.8 \cdot \operatorname{Din}-86.31 .
$$

\subsection{Results}

In this study, the MINLP model of each step was solved using the DICOPT solver of GAMS software [36] on a $3.00 \mathrm{GHz}$ personal computer (PC) with $16 \mathrm{~GB}$ random-access memory (RAM). The computational time of the three steps was $11.2 \mathrm{~s}, 0.4 \mathrm{~s}$, and $4.6 \mathrm{~s}$, respectively. The results of the first step are shown in Figures 4 and 5 and Table 6. In the HEN, the waste heat of all hot streams is recovered. There are 13 heat exchangers; 11 exchangers (blue) operate for the maximum cooling potential, and 12 exchangers (red) operate for the maximum heating potential. The district heating potential of the plant is $Q^{D H, \max }=27,016 \mathrm{~kW}$, while the district cooling potential is $Q^{D C, \max }=8641 \mathrm{~kW}$.

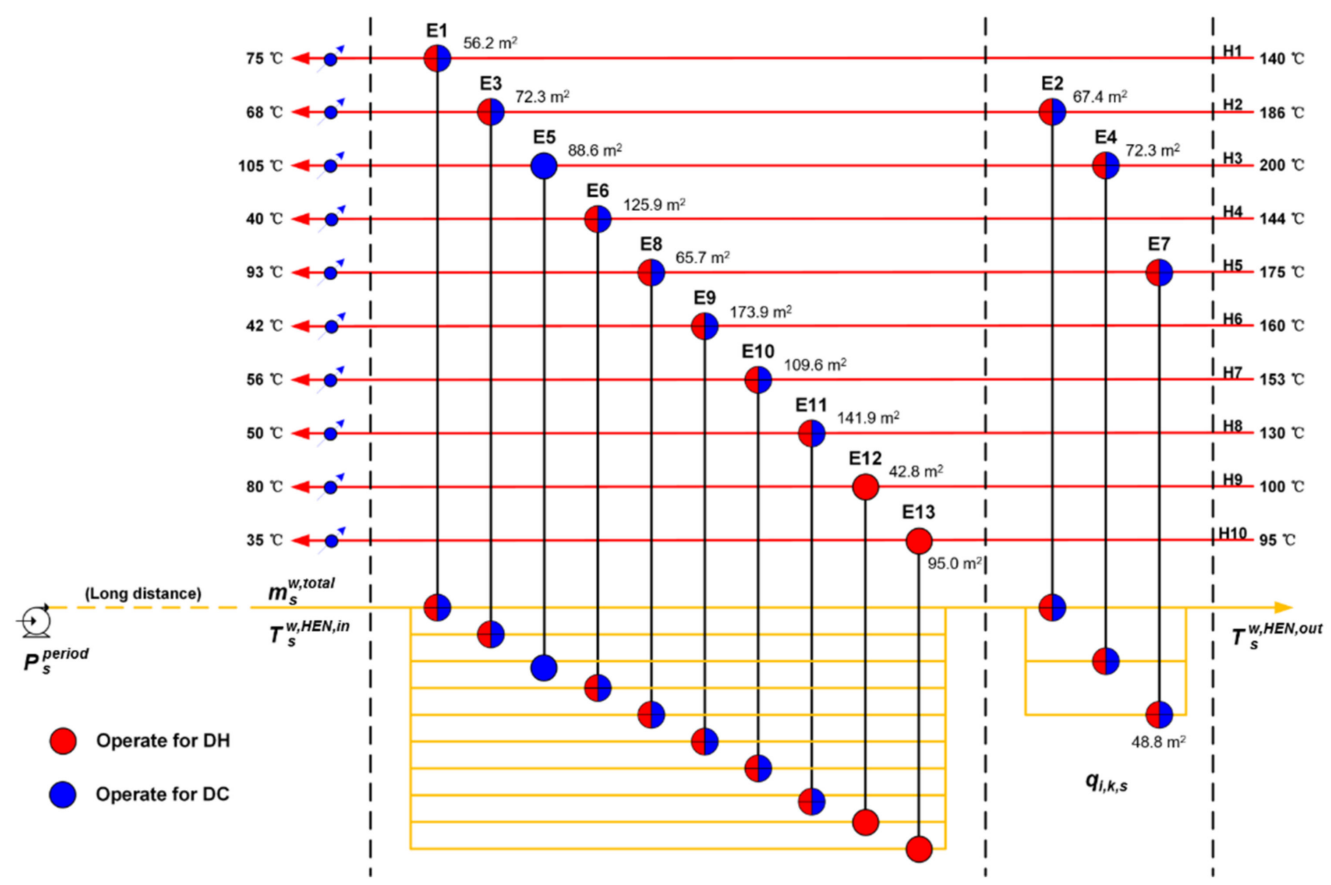

Figure 4. The heat exchanger network (HEN) of the first step.

The scheme obtained in the second step for the DES system is shown in Table 7, in which "-" means that the consumer has no cooling or heating demand, while " 0 " represents that the consumer has cooling or heating demand but it is not supplied by the plant. In this scheme, the actual total heating capacity of the plant in winter is $26,229.1 \mathrm{~kW}$, and the actual total cooling capacity in summer is $8552.3 \mathrm{~kW}$. The actual capacity of energy supply reaches more than $95 \%$ of the potential. In spring and autumn, the total demand of cooling in this region is relatively small and can be fully supplied by the plant $(5264.1 \mathrm{~kW})$. 


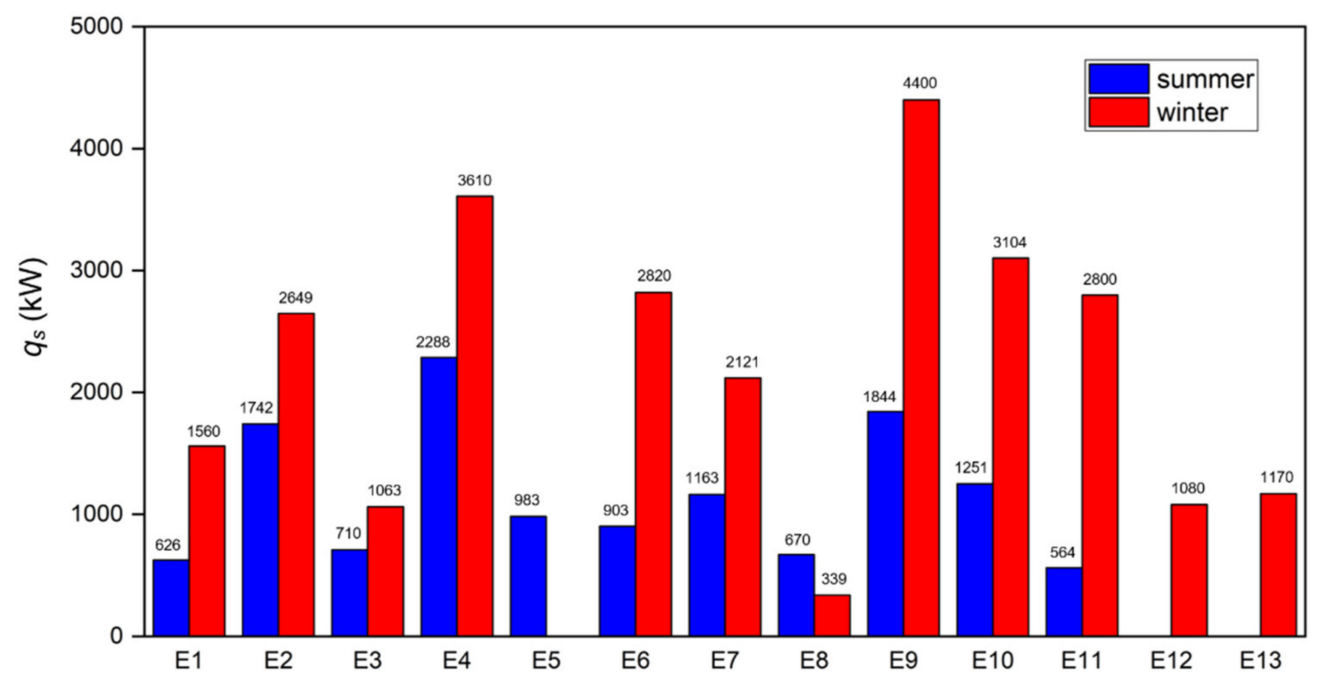

Figure 5. Heat load of heat exchangers in the first step.

Table 6. Operation parameters of the first step.

\begin{tabular}{|c|c|c|c|c|c|c|c|c|}
\hline$s$ & $\begin{array}{c}m_{s}^{w, t o t a l} \\
(\mathrm{~kg} / \mathrm{s})\end{array}$ & $\begin{array}{c}T_{s}^{w, H E N, i n} \\
\quad\left({ }^{\circ} \mathrm{C}\right)\end{array}$ & $\begin{array}{c}T_{s}^{w, H E N, o u t} \\
\quad\left({ }^{\circ} \mathrm{C}\right)\end{array}$ & $\begin{array}{c}P_{s}^{\text {period }} \\
(\mathbf{k W})\end{array}$ & $\begin{array}{c}Q_{s}^{\text {recover }} \\
(\mathbf{k W})\end{array}$ & $\begin{array}{c}Q_{s}^{D H} \\
(\mathbf{k W})\end{array}$ & $\begin{array}{c}Q_{s}^{D C} \\
(\mathbf{k W})\end{array}$ & $\mathrm{COP}_{\mathrm{s}}$ \\
\hline summer & 177.4 & 40.0 & 75.7 & 4.204 & 27,016 & 27,016 & - & - \\
\hline winter & 180.2 & 103.9 & 121.0 & 5.348 & 12,744 & - & 8641 & 0.678 \\
\hline
\end{tabular}

Table 7. The result data of the second step.

\begin{tabular}{|c|c|c|c|c|}
\hline \multirow{2}{*}{$j$} & \multicolumn{4}{|c|}{$y_{j, s}^{\text {supply }} \cdot E_{j, s}^{\text {supply }}(\mathbf{k W})$} \\
\hline & $s=$ Spring & $s=$ Summer & $s=$ Autumn & $s=$ Winter \\
\hline N1 & - & - & - & 4214.6 \\
\hline N2 & 1065.4 & 0 & 1065.4 & 0 \\
\hline N3 & - & 1931.2 & - & 0 \\
\hline N4 & - & - & - & 7578.4 \\
\hline N5 & 2200.4 & 4400.7 & 2200.4 & 5500.9 \\
\hline N6 & 1998.3 & 2220.4 & 1998.3 & 0 \\
\hline N7 & - & - & - & 8935.2 \\
\hline N8 & - & 0 & - & 0 \\
\hline
\end{tabular}

The operation scheme for the WHR in the year is provided by the third step, which is shown in Figures 6 and 7 and Table 8. There are 11 heat exchangers; six exchangers (green) operate in spring and autumn, nine exchangers (blue) operate in summer, and 10 exchangers (red) operate in winter.

Economic data of the second and third steps of this case are shown in Table 9.

Table 8. Operation parameters of the third step.

\begin{tabular}{|c|c|c|c|c|c|c|}
\hline$s$ & $\begin{array}{c}m_{s}^{w, t o t a l} \\
(\mathrm{~kg} / \mathrm{s})\end{array}$ & $\begin{array}{c}T_{s}^{w, H E N, \text { in }} \\
\quad\left({ }^{\circ} \mathrm{C}\right)\end{array}$ & $\begin{array}{c}T_{s}^{w, H E N, o u t} \\
\left({ }^{\circ} \mathrm{C}\right)\end{array}$ & $\begin{array}{c}P_{s}^{\text {period }} \\
(\mathbf{k W})\end{array}$ & $\begin{array}{c}Q_{s}^{\text {recover }} \\
(\mathbf{k W})\end{array}$ & $\mathrm{COP}_{\mathrm{s}}$ \\
\hline spring and autumn & 156.6 & 101.5 & 114.3 & 3.659 & 8420.0 & 0.625 \\
\hline summer & 156.3 & 105.2 & 124.0 & 4.391 & $12,341.0$ & 0.693 \\
\hline winter & 160.4 & 40.0 & 78.9 & 5.097 & $26,229.1$ & 0 \\
\hline
\end{tabular}




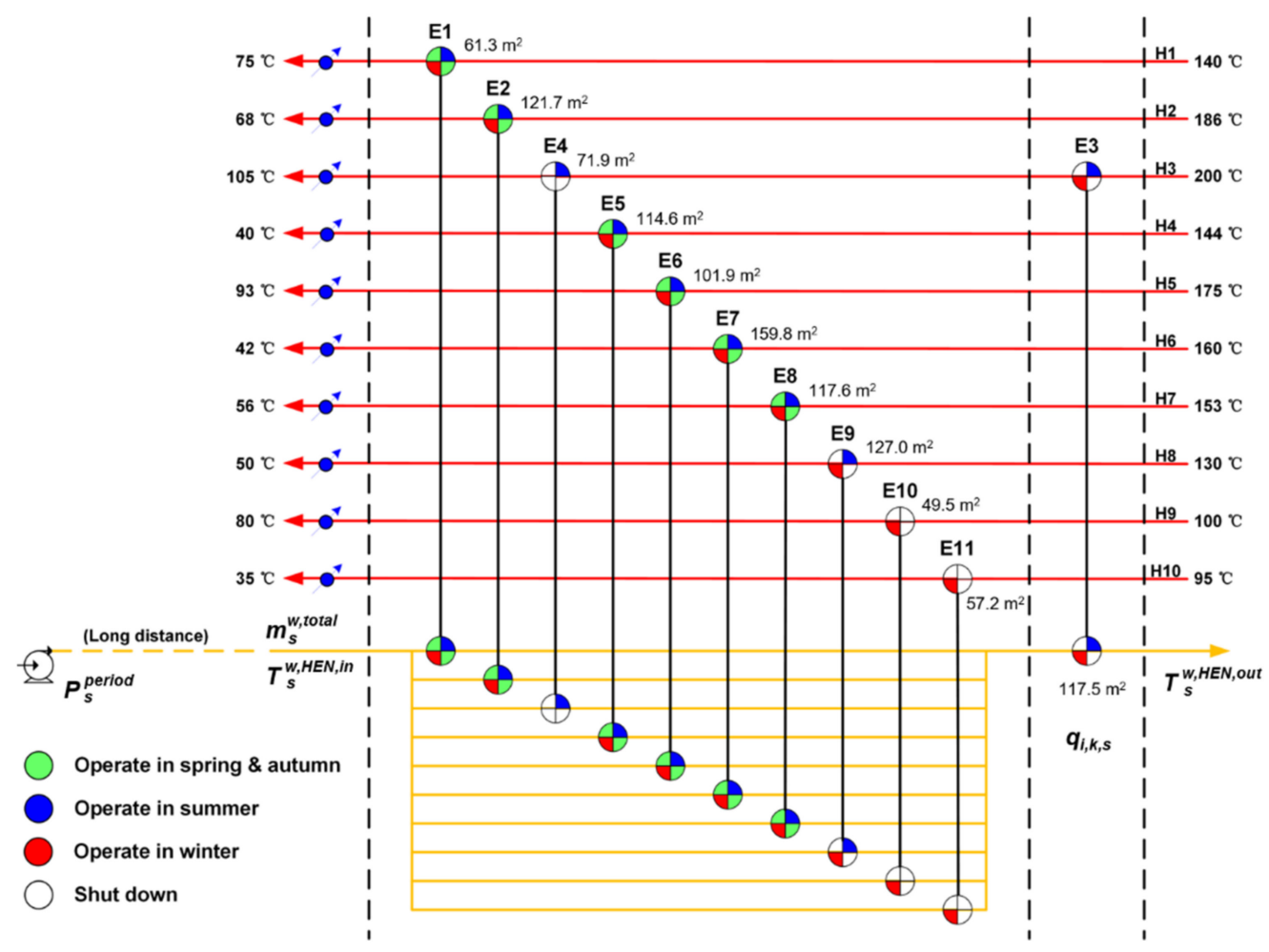

Figure 6. The HEN of the third step.

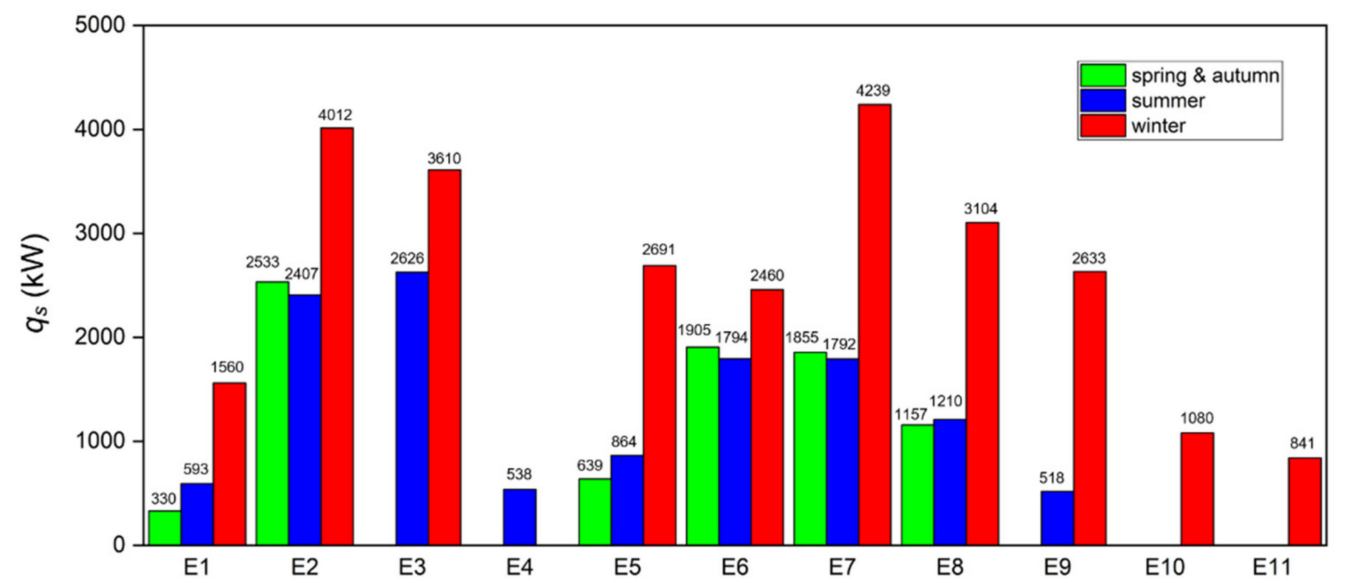

Figure 7. Heat load of heat exchangers in the third step.

Table 9. The economic data.

\begin{tabular}{ccccc}
\hline$I^{\text {DHC }}$ (USD) & $C^{\text {pipe,DHC }}$ (USD) & $C^{\text {station }}$ (USD) & TAP (USD) & \\
$9,953,280$ & $3,168,591$ & $1,007,949$ & $5,776,740$ & \\
$C^{c u}$ (USD) & $C^{\text {exchanger }}$ (USD) & $C^{\text {pipe,loop }}$ (USD) & $C^{\text {pump }}$ (USD) & TAC' (USD) \\
185,439 & 75,447 & 96,061 & 18,312 & 375,259 \\
\hline
\end{tabular}

\subsection{Discussion}

In this case, it can be calculated that, when the low-grade waste heat is not recovered, the annual cost of cold utility is $4.204 \times 10^{5}$ USD. By integrating waste heat with the DHC system, this number drops to $1.854 \times 10^{5}$ USD with a decrease of $55.9 \%$. Especially in winter when the capacity of waste heat utilization is the largest, the cost of cold utility drops from $1.401 \times 10^{5}$ USD to $8.985 \times 10^{3}$ USD, with a decrease of $93.6 \%$. The annual income of the plant by district heating and cooling is up to $9.953 \times 10^{6}$ USD. The above two parts 
of revenue indicate that the annual benefit of the integration amounts to $1.019 \times 10^{7} \mathrm{USD}$, while the total annual cost is $4.366 \times 10^{6}$ USD; therefore, the annual profit of the plant is $5.822 \times 10^{6}$ USD. It is proven that there is a strong motivation to integrate low-grade waste heat into the DHC system.

The district cooling potential of the plant $Q^{D C, \max }$ is only about one-third of the district heating potential $Q^{D H, m a x}$. There are two reasons for this difference. First, the hot water used for absorption refrigeration requires a higher temperature $\left(>100^{\circ} \mathrm{C}\right)$; therefore, less heat can be recovered. In this case, the temperature of hot streams $\mathrm{H} 9$ and $\mathrm{H} 10$ cannot meet the requirement of refrigeration; their heat is not recovered in spring, summer, and autumn. Second, the COP of a single-effect $\mathrm{LiBr} / \mathrm{H}_{2} \mathrm{O}$ absorption chiller is lower than 1.0; therefore, the cold capacity is less than the heat recovered. Both reasons make $Q^{D C \text {,max }}$ lower than $Q^{D H, \max }$. If it is desired to obtain a large cooling capacity, the temperature of hot water entering the chiller $T_{s}^{\tilde{w}, \text { chiller, in }}$ (namely, the outlet temperature of hot water in HEN $T_{s}^{w, H E N, o u t}$ ) should be in a moderate range. It can be seen from Equation (5) that, when

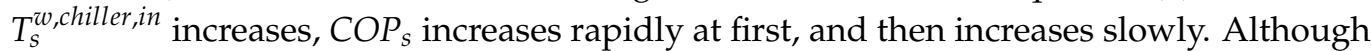
the efficiency of the chiller increases simultaneously, the corresponding temperature of hot water leaving the chiller $T_{s}^{w \text {, chiller,out }}$ (i.e., the inlet temperature of hot water in HEN $\left.T_{s}^{w, H E N, i n}\right)$ rises correspondingly, leading to a reduction in recovered heat. Therefore, there is an optimal temperature of hot water entering the chiller to ensure the largest cooling capacity.

It can be calculated that the energy loss in the DHC system is about $9 \%$. By considering energy loss and piping cost, consumers with low energy demand and long distance from the plant, such as consumer N8 in winter, are not recommended to be supplied by the plant. A consumer where the cooling demand in spring/autumn is close to the demand in summer, such as consumers N5 and N6 in this case, is suggested to be preferentially supplied by the plant. This can be explained as follows: the DC pipeline can be shared in three periods, whereby more benefit can be acquired under the same investment.

In this case, there is a wide range of temperature of heat streams. If there is only one stage in HEN, the cascade recovery of waste heat cannot be realized. When the number of stages grows, the hot water flows in multistage series and the pressure drop increases, whereby a greater cost of pump is needed. Combining the above two factors, it is reasonable that two stages exist in the HEN. Two heat exchangers exist in hot stream $\mathrm{H} 3$, since it has the highest temperature and cascade use of heat is needed. In winter, the heat of hot streams $\mathrm{H} 9$ and $\mathrm{H} 10$ is used to increase the capacity of heat recovery in the low-grade stage. At this time, the heat exchanger $\mathrm{E} 4$ in the low-grade stage for heat stream $\mathrm{H} 3$ is shut down, while the heat of $\mathrm{H} 3$ is fully recovered by heat exchanger E3 in high-grade stage. On the other hand, in spring, summer, and autumn, the temperatures of hot streams H9 and H10 are too low to meet the requirement of absorption refrigeration; thus, the heat exchangers E10 and E11 are shut down. At this time, the heat exchanger E4 is turned on so that the total amount of heat recovery in the low-grade stage increases. The above operation keeps the ratio of the heat recovery capacity in the two stages basically unchanged to make the total area smaller.

In the WHR system, the outlet temperature of hot water $T_{s}^{w, H E N, \text { out }}$ is an important variable to be optimized, which has a direct impact on the results. As mentioned, a medium $T_{s}^{w, H E N, \text { out }}$ should be adopted in summer when the cooling capacity is large. On the other hand, in spring and autumn, the cooling capacity is relatively small. Because the waste heat resource is sufficient in the periods to achieve the required cooling capacity, a lower $T_{s}^{w, H E N, \text { out }}$ can be adopted. Although the COP of the chiller is relatively low, waste heat can be recovered as much as possible. By doing this, the cost of cold utility can be reduced. In spring and autumn, the difference between the inlet and outlet temperature of hot water in HEN is relatively small, and the task of waste heat recovery is completed in one stage to reduce pressure drop. When the system is operated in winter, a tradeoff between $C^{\text {exchanger }}$ and distance-related cost (including $C^{\text {pipe,loop }}$ and $C^{\text {pump }}$ ) under the same capacity of heat recovery should be made. When $T^{w, H E N, \text { in }}$ is fixed at $40^{\circ} \mathrm{C}$, the heat transfer temperature 
difference decreases with the rise in $T^{w, H E N, o u t}$, and the total heat transfer area needed for exchangers increases, so that the $C^{\text {exchanger }}$ increases. Meanwhile, $C^{\text {pipe,loop }}$ and $C^{\text {pump }}$ can be reduced due to the reduction in $m^{w, t o t a l}$. In this study, the scheme of the WHR system in winter should cooperate with that in the other three periods, and the temperature of hot water gained in winter is moderate $\left(78.9^{\circ} \mathrm{C}\right)$. It can be found that the total mass flow rate of hot water in each season is almost equal, indicating that the velocity of hot water is appropriate in each period.

In the third step, if the operation scheme of WHR system is not optimized, the waste heat of hot streams is recovered by hot water in a purely parallel structure. In spring, summer, and autumn, the inlet and outlet temperatures of the hot water are the same as that in the first step. In winter, the outlet temperature of hot water is fixed at $85{ }^{\circ} \mathrm{C}$ as in [20]. It can be calculated that the $T A C^{\prime}$ would change to 381,546 USD, which is greater than the optimal solution. Therefore, it is of significance to optimize the multiperiod operation scheme of the WHR system. According to the previous discussion, $T_{s=\text { summer }}^{w, H E N \text {,out }}$ can be regarded as the most impactful variable. A sensitivity analysis of $T_{S=\text { summer }}^{w, H E N \text {,out }}$ and $T A C^{\prime}$ was performed after the third step. The result is shown in Figure 8. The range of $T_{S=\text { summer }}^{w, H E N, \text { out }}$ is relatively narrow. In this case, if the value of $T_{s=\text { summer }}^{w, H E N, \text { out }}$ exceeds the range in Figure 8, the district cooling task in summer cannot be accomplished. On the left and right sides of $124^{\circ} \mathrm{C}$ in the figure, a higher cost of pipeline and a higher cost of cold utility respectively led to a worse solution.

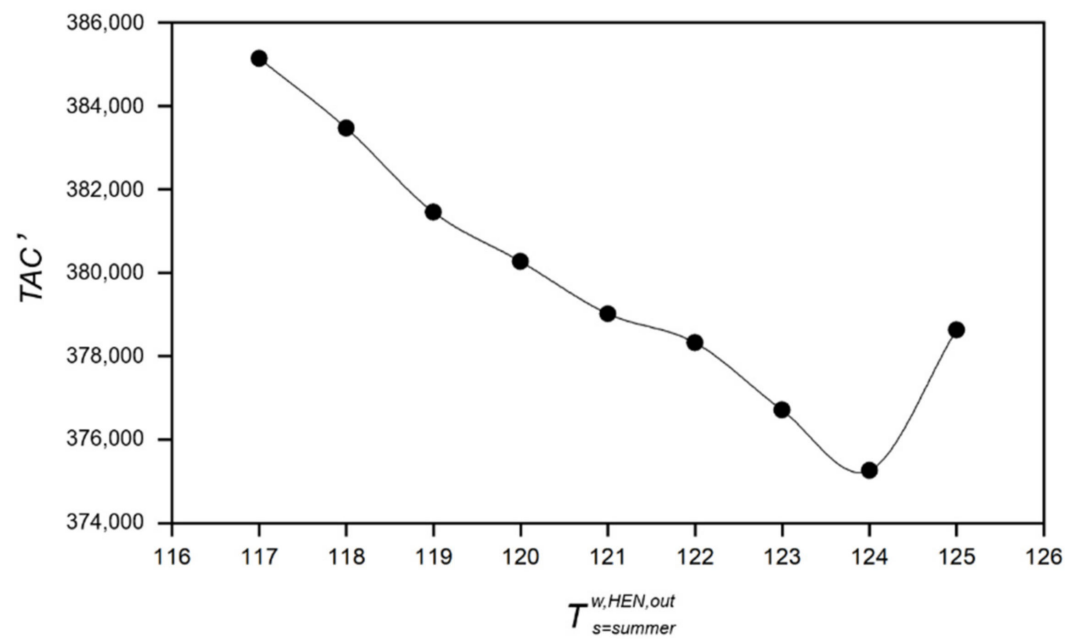

Figure 8. Sensitivity analysis of $T_{S=\text { summer }}^{w, H E N, \text { out }}$.

\section{Conclusions}

A systematic framework method for utilizing industrial low-grade heat in DHC with a multiperiod condition was proposed. Both design and operation variables in different periods could be determined. A case study was carried out, and the results showed that the heat exchanger network in the WHR system is not a simple parallel structure. A two-stage series/parallel network of intermediate fluids should be established. In different periods, the operation plan of heat exchangers should be flexible, while the total flow rate of hot water should be basically the same. The temperatures of hot water obtained in WHR $\left(T_{S}^{w, H E N, o u t}\right)$ should be different in periods when the cooling capacities are significantly different. In seasons with a larger cooling capacity, $T_{S}^{w, H E N, o u t}$ is suggested to be close to $121{ }^{\circ} \mathrm{C}$, while it can take a smaller value in seasons with a smaller cooling capacity. In this case, the total annual cost of WHR system (TAC') will increase by more than 6000 USD without the above multiperiod operation optimization. The cost saving proves the worth of the third step. In a DES system, priority should be given to the consumers where (1) the cooling demand in spring/autumn is close to that in summer, and (2) the distance from the plant is relatively short while the heating demand is large. The economic data of the case 
study show that the total annual benefit of the integration is up to $1.019 \times 10^{7}$ USD, which is greater than the total annual cost $4.366 \times 10^{6}$ USD. Strong motivation for an integration of low-grade industrial waste heat and a DHC system is indicated.

Author Contributions: Conceptualization, X.F. and Y.W.; methodology, Y.W.; software, L.Z.; validation, L.Z. and Y.W.; formal analysis, Y.W.; investigation, L.Z.; resources, X.F.; data curation, L.Z.; writing-original draft preparation, L.Z.; writing—review and editing, Y.W.; visualization, L.Z.; supervision, Y.W.; project administration, Y.W.; funding acquisition, Y.W. All authors have read and agreed to the published version of the manuscript.

Funding: Financial support from the National Natural Science Foundation of China under Grant No. 22022816 and 22078358 is gratefully acknowledged.

Data Availability Statement: Not applicable.

Conflicts of Interest: The authors declare no conflict of interest.

\section{Nomenclature}

\begin{tabular}{|c|c|}
\hline \multicolumn{2}{|c|}{ Abbreviations } \\
\hline DES & District energy supply \\
\hline DC & District cooling \\
\hline $\mathrm{DH}$ & District heating \\
\hline $\mathrm{DHC}$ & District heating and cooling \\
\hline HEN & Heat exchanger network \\
\hline HI & Heat Integration \\
\hline HRL & Heat recovery loop \\
\hline MP & Mathematical programming \\
\hline MINLP & Mixed integer nonlinear programming \\
\hline WHR & Waste heat recovery \\
\hline \multicolumn{2}{|c|}{ Subscripts } \\
\hline$i$ & Hot stream index \\
\hline$j$ & Consumer index \\
\hline$s$ & Period index \\
\hline \multicolumn{2}{|c|}{ Parameters and Variables } \\
\hline$A_{i, k, s}^{\text {period }}$ & Area of heat exchanger in period $\left(\mathrm{m}^{2}\right)$ \\
\hline$A_{i, k}^{\text {design }}$ & Design area of heat exchanger $\left(\mathrm{m}^{2}\right)$ \\
\hline$A f^{n}$ & Annual factor \\
\hline$C^{c u}$ & Cost of cold utility (USD) \\
\hline$C^{\text {exchanger }}$ & Capital cost of heat exchangers (USD) \\
\hline$C^{\text {pipe,loop }}$ & Capital cost of pipeline in HRL (USD) \\
\hline$C^{\text {pipe,DHC }}$ & Capital cost of pipeline in DHC system (USD) \\
\hline$C^{\text {pump }}$ & Total cost of pump (USD) \\
\hline$C^{\text {pump,cap }}$ & Capital cost of pump (USD) \\
\hline$C^{\text {pump,op }}$ & Operation cost of pump (USD) \\
\hline$C^{\text {station }}$ & Capital cost of the station (USD) \\
\hline $\mathrm{COP}_{S}$ & Coefficient of performance of the absorption chiller \\
\hline$c p^{w}$ & Specific heat capacity of water $\left(\mathrm{kJ} \cdot \mathrm{kg}^{-1} \cdot{ }^{\circ} \mathrm{C}^{-1}\right)$ \\
\hline$d t_{i, k, s}$ & Temperature approach of heat exchanger $\left({ }^{\circ} \mathrm{C}\right)$ \\
\hline$E_{j, s}^{n e e d}$ & Energy demand of consumer $(\mathrm{kW})$ \\
\hline$E_{j, s}^{\text {supply }}$ & Actual energy capacity should be supplied to consumer $(\mathrm{kW})$ \\
\hline$E_{S}^{\text {total }}$ & Total capacity of energy supplied $(\mathrm{kW})$ \\
\hline$F_{i}^{h s}$ & Flow capacity of hot stream $\left(\mathrm{kW} \cdot{ }^{\circ} \mathrm{C}-1\right)$ \\
\hline$h^{w}$ & Film heat transfer coefficient of hot water $\left(\mathrm{kW} \cdot \mathrm{m}^{-2} \cdot{ }^{\circ} \mathrm{C}^{-1}\right)$ \\
\hline$h_{i}^{h s}$ & Film heat transfer coefficient of hot stream $\left(\mathrm{kW} \cdot \mathrm{m}^{-2} \cdot{ }^{\circ} \mathrm{C}^{-1}\right)$ \\
\hline$I^{D H C}$ & Income of the plant by district heating and cooling (USD) \\
\hline$L^{\text {loop }}$ & Distance between station and production area $(\mathrm{m})$ \\
\hline$L_{j}^{\text {consumer }}$ & Distance between the plant and consumer (m) \\
\hline
\end{tabular}




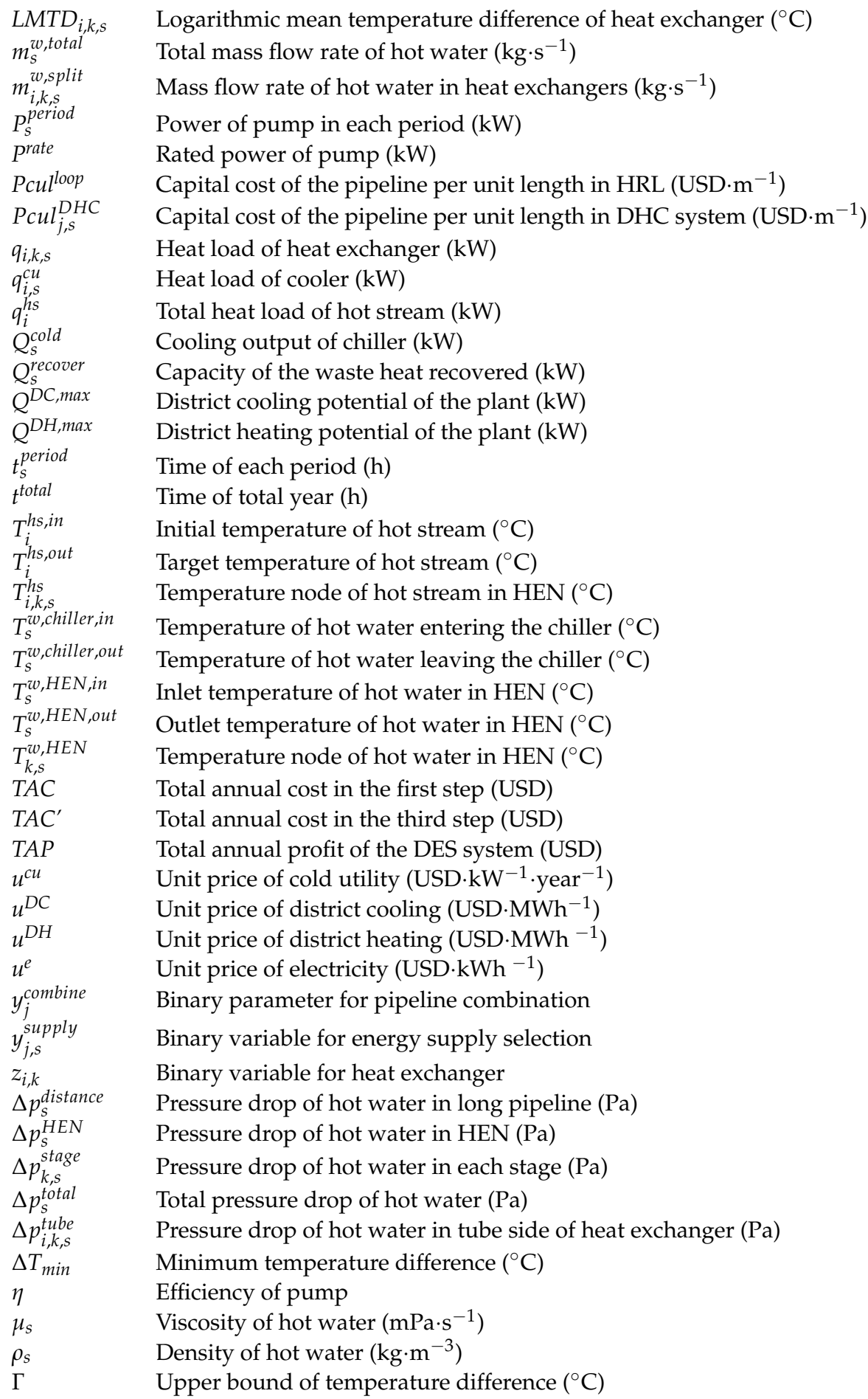

\section{References}

1. Ji, C.; Qin, Z.; Dubey, S.; Choo, F.H.; Duan, F. Three-dimensional transient numerical study on latent heat thermal storage for waste heat recovery from a low temperature gas flow. Appl. Energy 2017, 205, 1-12. [CrossRef]

2. Klemeš, J.J.; Kravanja, Z. Forty years of Heat Integration: Pinch Analysis (PA) and Mathematical Programming (MP). Curr. Opin. Chem. Eng. 2013, 2, 461-474. [CrossRef]

3. Linnhoff, B.; Hindmarsh, E. The pinch design method for heat exchanger networks. Chem. Eng. Sci. 1983, 38, 745-763. [CrossRef]

4. Floudas, C.A.; Ciric, A.R.; Grossmann, I.E. Automatic synthesis of optimum heat exchanger network configurations. AIChE J. 1986, 32, 276-290. [CrossRef]

5. Yee, T.F.; Grossmann, I.E. Simultaneous optimization models for heat integration II: Heat exchanger network synthesis. Comput. Chem. Eng. 1990, 14, 1165-1184. [CrossRef] 
6. Shang, J.; Ji, Z.; Qiu, M.; Ma, L. Multi-objective optimization of high-sulfur natural gas purification plant. Pet. Sci. 2019, 16, 1430-1441. [CrossRef]

7. Forman, C.; Muritala, I.K.; Pardemann, R.; Meyer, B. Estimating the global waste heat potential. Renew. Sustain. Energy Rev. 2016, 57, 1568-1579. [CrossRef]

8. Van de Bor, D.M.; Infante Ferreira, C.A.; Kiss, A.A. Low grade waste heat recovery using heat pumps and power cycles. Energy 2015, 89, 864-873. [CrossRef]

9. Fang, H.; Xia, J.; Zhu, K.; Su, Y.; Jiang, Y. Industrial waste heat utilization for low temperature district heating. Energy Policy 2013, 62, 236-246. [CrossRef]

10. Huang, F.; Zheng, J.; Baleynaud, J.M.; Lu, J. Heat recovery potentials and technologies in industrial zones. J. Energy Inst. 2017, 90, 951-961. [CrossRef]

11. Gao, X.; Yin, X.; Yang, S.; Yang, D. Improved organic rankine cycle system coupled with mechanical vapor recompression distillation for separation of benzene-toluene mixture. Process Integr. Optim. Sustain. 2019, 3, 189-198. [CrossRef]

12. Xia, L.; Liu, R.; Zeng, Y.; Zhou, P.; Liu, J.; Cao, X.; Xia, S. A review of low-temperature heat recovery technologies for industry processes. Chin. J. Chem. Eng. 2019, 27, 2227-2237. [CrossRef]

13. Garcia, S.I.; Garcia, R.F.; Carril, J.C.; Garcia, D.I. A review of thermodynamic cycles used in low temperature recovery systems over the last two years. Renew. Sustain. Energy Rev. 2017, 81, 760-767. [CrossRef]

14. Lund, H.; Werner, S.; Wiltshire, R.; Svendsen, S.; Thorsen, J.E.; Hvelplund, F.; Mathiesen, B.V. 4th generation district heating (4gdh): Integrating smart thermal grids into future sustainable energy systems. Energy 2014, 68, 1-11. [CrossRef]

15. Li, Y.; Rezgui, Y.; Zhu, H. District heating and cooling optimization and enhancement-Towards integration of renewables, storage and smart grid. Renew. Sustain. Energy Rev. 2017, 72, 281-294. [CrossRef]

16. Tveit, T.M.; Aaltola, J.; Laukkanen, T.; Laihanen, M.; Fogelholm, C.J. A framework for local and regional energy system integration between industry and municipalities-Case study UPM-Kymmene Kaukas. Energy 2006, 31, 2162-2175. [CrossRef]

17. Kapil, A.; Bulatov, I.; Smith, R.; Kim, J.K. Process integration of low grade heat in process industry with district heating networks. Energy 2012, 44, 11-19. [CrossRef]

18. Fang, H.; Xia, J.; Jiang, Y. Key issues and solutions in a district heating system using low-grade industrial waste heat. Energy 2015, 86, 589-602. [CrossRef]

19. Wang, J.; Wang, Z.; Zhou, D.; Sun, K. Key issues and novel optimization approaches of industrial waste heat recovery in district heating systems. Energy 2019, 188, 116005. [CrossRef]

20. Fitó, J.; Hodencq, S.; Ramousse, J.; Wurtz, F.; Stutz, B.; Debray, F.; Vincent, B. Energy- and exergy-based optimal designs of a low-temperature industrial waste heat recovery system in district heating. Energy Convers. Manag. 2020, 211, 112753. [CrossRef]

21. Khosravi, A.; Laukkanen, T.; Vuorinen, V.; Syri, S. Waste heat recovery from a data centre and 5G smart poles for low-temperature district heating network. Energy 2021, 218, 119468. [CrossRef]

22. Srikhirin, P.; Aphornratana, S.; Chungpaibulpatana, S. A review of absorption refrigeration technologies. Renew. Sustain. Energy Rev. 2011, 5, 343-372. [CrossRef]

23. Liew, P.Y.; Walmsley, T.G.; Wan Alwi, S.R.; Manan, Z.A.; Klemeš, J.J.; Varbanov, P.S. Integrating district cooling systems in Locally Integrated Energy Sectors through Total Site Heat Integration. Appl. Energy 2016, 184, 1350-1363. [CrossRef]

24. Zhang, L.; Wang, Y.; Feng, X. Design and Operation Optimization of Industrial Waste Heat Recovery for District Heating and Cooling. In Proceedings of the 23rd Conference on Process Integration, Modelling and Optimisation for Energy Saving and Pollution Reduction (PRES'20), Xi'an, China, 17-21 August 2020; p. 265.

25. Söderman, J. Optimisation of structure and operation of district cooling networks in urban regions. Appl. Therm. Eng. 2007, 27, 2665-2676. [CrossRef]

26. Chang, C.; Chen, X.; Wang, Y.; Feng, X. An efficient optimization algorithm for waste Heat Integration using a heat recovery loop between two plants. Appl. Therm. Eng. 2016, 105, 799-806. [CrossRef]

27. Arabkoohsar, A.; Andresen, G.B. Supporting district heating and cooling networks with a bifunctional solar assisted absorption chiller. Energy Convers. Manag. 2017, 148, 184-196. [CrossRef]

28. Wang, Y.; Wang, C.; Feng, X. Optimal match between heat source and absorption refrigeration. Comput. Chem. Eng. 2017, 102, 268-277. [CrossRef]

29. Chen, J.J.J. Comments on improvements on a replacement for the logarithmic mean. Chem. Eng. Sci. 1987, 42, 2488-2489. [CrossRef]

30. Verheyen, W.; Zhang, N. Design of flexible heat exchanger network for multi-period operation. Chem. Eng. Sci. 2006, 61, 7730-7753.

31. Peters, M.S.; Timmerhaus, K.D.; West, R.E. Plant Design and Economics for Chemical Engineers, 5th ed.; McGraw-Hill: Boston, MA, USA, 2003.

32. Stijepovic, M.Z.; Linke, P. Optimal waste heat recovery and reuse in industrial zones. Energy 2011, 36, $4019-4031$.

33. Soltani, H.; Shafiei, S. Heat exchanger networks retrofit with considering pressure drop by coupling genetic algorithm with LP (linear programming) and ILP (integer linear programming) methods. Energy 2011, 36, 2381-2391. [CrossRef]

34. Best, R.E.; Rezazadeh Kalehbasti, P.; Lepech, M.D. A novel approach to district heating and cooling network design based on life cycle cost optimization. Energy 2020, 194, 1-16. [CrossRef]

35. Jabbari, B.; Tahouni, N.; Ataei, A.; Panjeshahi, M.H. Design and optimization of CCHP system incorporated into kraft process, using Pinch Analysis with pressure drop consideration. App. Therm. Eng. 2013, 61, 88-97. [CrossRef]

36. Rosenthal, R.E. GAMS—A User's Guide; GAMS Development Corporation: Washington, DC, USA, 2008. 